\title{
Nuevas formas de cooperación territorial: las organizaciones asociativas de entes locales ${ }^{1}$
}

\author{
Marc Vilalta Reixach
}

Sumario: I. INTRODUCCIÓN: DELIMITACIÓN DEL OBJETO DE ESTUDIO. II. EL DERECHO DE ASOCIACIÓN EN EL ÁMBITO LOCAL; 1. El reconocimiento del derecho de asociación de los entes locales; 2. La peculiar naturaleza de las organizaciones asociativas de entes locales. III. EL MARCO NORMATIVO, EN ESPECIAL EN CATALUÑA. IV. SOBRE LAS POSIBILIDADES DE INTRODUCIR SUPUESTOS DE DIFERENCIACIÓN EN EL RÉGIMEN JURÍDICO DE ORGANIZACIÓN Y FUNCIONAMIENTO. 1. La potestad de las entidades locales para configurar el régimen jurídico interno de las organizaciones asociativas de entes locales: la libertad positiva de asociación. 2. Limitaciones a la potestad de las entidades locales por configurar el régimen jurídico interno de las organizaciones asociativas de entes locales; 2.1. La asociación como forma de colaboración. 2.2. Principios estructurales: el carácter democrático; 2.2.1. La organización interna; 2.2.2. Derechos de los entes asociados. V. CONCLUSIÓN. VI. ADDENDA FINAL.

\section{INTRODUCCIÓN: DELIMITACIÓN DEL OBJETO DE ESTUDIO}

La Constitución española de 1978 (en adelante CE) configura a los municipios y a las provincias como una de las instancias básicas de la organización territorial del Estado, atribuyéndoles autonomía para la gestión de sus respectivos intereses. De esta manera, municipios y provincias se conciben no sólo como una mera organización administrativa, sino como un auténtico poder político, expresivo de los intereses de la colectividad local a la que representan.

Ahora bien, la propia complejidad y diversidad del mundo local, con una extensa tipología de entidades locales, la existencia de numerosos núcleos urbanos con una distribución irregular de la población ${ }^{2}$, así como la ampliación de la escala geográfica de la acción pública local, ha puesto de manifiesto

\footnotetext{
${ }^{1}$ El presente estudio tiene su origen en el curso «Organización territorial: igualdad y diversidad», impartido por los profesores Dr. Tomàs Font i Llovet y Dr. Alfredo Galán Galán, en el marco del programa de doctorado en Derecho de la Universidad de Barcelona durante el curso 2004/2005. A ellos quiero agradecerles, muy sinceramente, las observaciones realizadas y el hecho de que este trabajo haya podido ser finalmente publicado.

2 Un buen ejemplo de esta situación lo encontramos en la Comunidad Autónoma de Cataluña, formada por 946 municipios, de los cuales más de 500 tienen menos de 1000 habitantes y más de 750 tienen menos de 5000, por lo que casi un $80 \%$ de los municipios catalanes se pueden calificar como pequeños municipios. Pereira SolÉ, Albert: «El régimen local en la reforma del Estatuto de Autonomía de Cataluña», en Font i Llovet, Tomás (Dir.): Anuario del Gobierno Local 2004, Ed. Fundación Democracia y Gobierno Local- Instituto de Derecho Público, Barcelona 2005, p. 201.
} 
la necesidad de establecer nuevos mecanismos de cooperación interadministrativa, basados en la comunicación e interacción entre los diferentes actores públicos locales. Dichos mecanismos deben permitir a las distintas entidades públicas locales emprender acciones conjuntas, la realización de las cuales sería imposible desarrollar con una actuación individual.

En el contexto de un Estado complejo, como es el caso español, caracterizado por un alto grado de descentralización política, podemos afirmar que los gobiernos locales si pretenden defender y promocionar sus intereses particulares de forma efectiva, con la idea de mejorar no sólo su competitividad, sino también de garantizar la eficacia y la eficiencia en la actuación pública, necesitan establecer nuevas formas de cooperación mutua ${ }^{3}$. En este sentido, sin perjuicio de las posibilidades de relación singular de que disponen los distintos entes locales, estos nuevos instrumentos cooperativos deben permitirles articular una nueva forma de actuación organizada, representando con una voz unitaria sus respectivos intereses ante las instancias territoriales superiores (ya sean de ámbito autonómico, estatal o internacional).

Precisamente, una de las ideas que el Libro blanco para la reforma del gobierno local en España, elaborado por el Ministerio de Administraciones Públicas ${ }^{4}$, destaca con más insistencia es la percepción de que, dada la estructura del mapa municipal español y con el objetivo de conseguir la efectiva realización del principio de eficiencia, así como garantizar la adecuada prestación de los servicios públicos, la cooperación y la asociación entre los diferentes entes locales es una necesidad. Entendiendo, asimismo, que la reforma del actual marco normativo relativo al gobierno local debe orientarse hacia la potenciación de la cooperación intermunicipal.

Es en este punto en el que debemos situar el objeto de nuestro trabajo. Con él pretendemos aproximarnos, aunque sea brevemente, a una de las instituciones que en los últimos años ha experimentado un mayor desarrollo en nuestro sistema jurídico y social. Por lo que, lejos de verse como un fenómeno extraño, ha pasado a constituir una forma normal de organización interadministrativa de carácter local. Estas instituciones no son otras que las llamadas «asociaciones de entes locales».

Dichas asociaciones pueden definirse como aquellas agrupaciones de entes locales la finalidad de las cuales no se encuentra en la prestación de un determinado servicio público o en la ejecución en común de obras y servicios determinados (tal y como sucede en las mancomunidades de municipios o en los consorcios locales), sino en la promoción y defensa de los intereses comunes y específicos de sus miembros. Es decir, su actividad se concreta principalmente en la mediación, negociación y participación en órganos consultivos o deliberantes, tanto estatales como autonómicos. Realizando,

\footnotetext{
${ }^{3}$ Rodríguez Álvarez, José Manuel: Las Asociaciones de entidades locales en España, Ministerio de las Administraciones Públicas y Ministerio de la Presidencia, Madrid 2002, p. 32.
} 
asimismo, actividades y servicios en beneficio directo de las diferentes entidades asociadas (por ejemplo, a través de servicios de información y difusión, de asesoramiento o de formación) ${ }^{5}$.

En este sentido, las asociaciones de entes locales permiten a sus miembros afrontar y reflexionar sobre las políticas públicas locales de una manera transversal, imprescindible para desarrollar de forma eficiente la gestión pública. Permitiéndoles, de esta manera, mejorar su competitividad y racionalizar, en términos de eficacia, los recursos materiales utilizados. Constituyendo, al mismo tiempo, una garantía de equilibrio territorial y de solidaridad $^{6}$.

Aún así, debemos matizar que nuestro estudio no pretende abarcar el análisis de todo el régimen jurídico de estas instituciones, sino que parte de una doble limitación: en primer lugar, pretende centrar su atención en el ámbito territorial de Cataluña, donde, como veremos, este tipo de asociaciones dispone de una regulación específica contenida principalmente en el Texto refundido de la Ley municipal y de régimen local de Cataluña (en adelante, TrLM). Y, en segundo lugar, nuestro trabajo pretende centrarse en examinar una cuestión muy específica, como es la posibilidad de introducir supuestos de diferenciación dentro del régimen jurídico-subjetivo de dichas asociaciones.

\section{EL DERECHO DE ASOCIACIÓN EN EL ÁMBITO LOCAL}

Antes de avanzar en nuestra exposición, creemos conveniente detenernos un momento a examinar cual es el fundamento jurídico que nos permite reconocer a los diferentes entes locales la posibilidad de agruparse en asociaciones para la defensa y promoción de sus intereses comunes.

En este punto, nos limitaremos a plantear una serie de reflexiones que pueden ayudarnos a comprender mejor su naturaleza jurídica, siendo conscientes, sin embargo, de que el completo tratamiento de esta cuestión requiere un análisis mucho más detallado y exhaustivo, que la propia concepción del presente trabajo nos impide desarrollar.

Podemos empezar recordando que ha sido el propio Tribunal Constitucional

\footnotetext{
${ }^{4}$ Ministerio de Administraciones Públicas: Libro Blanco para la reforma del Gobierno Local en España, [En línea], Ministerio de Administraciones Públicas, Secretaría de Estado de Cooperación Territorial, julio 2005.

http://www.map.es/servicios_al_ciudadano/entes_locales/libro_blanco/common/Libro_Blanco_local.pdf

5 Rodríguez Álvarez, José Manuel: Las asociaciones... Op. Cit., p. 80.

${ }^{6}$ Sobre la importancia de la cooperación territorial en el ámbito municipal y la articulación de ésta en el contexto europeo, puede consultarse el trabajo de HiLdebrand ScHEID, Andreas: «Les xarxes de ciutats. Un instrument emergent de cooperació intermunicipal a Europa» en Síntesis, núm. 10, Diputación de Barcelona, Barcelona 2005.
} 
el que, en una jurisprudencia muy trabajada pero, a veces, poco clara, ha reconocido la posibilidad que las personas jurídicas puedan ser titulares de los derechos fundamentales y de las libertades públicas reconocidas por el ordenamiento jurídico ${ }^{7}$. Si bien se afirma que únicamente pueden serlo en la medida que la naturaleza de estos derechos y libertades así lo permita.

Es decir, a pesar de que, desde un punto de vista constitucional, exista un reconocimiento, a veces expreso y a veces implícito, de la titularidad por parte de las personas jurídicas de determinados derechos fundamentales, esta capacidad, reconocida en abstracto, en el caso de las personas jurídicas públicas debe ser delimitada y concretada a la vista de cada derecho fundamental.

En este sentido, el Tribunal Constitucional, en la STC 139/1995, de 26 de septiembre (ponente: D. Manuel Jiménez de Parga y Cabrera), precisa que «no son sólo los fines de una persona jurídica los que condicionan su titularidad de derechos fundamentales, sino también la naturaleza concreta del derecho fundamental considerado» (F.J. 4).

\section{El reconocimiento del derecho de asociación de los entes locales}

Centrándonos ya en el derecho de asociación, nos interesa destacar, en primer lugar, que la determinación de su titularidad adquiere una especial trascendencia. Así, se afirma que este derecho constituye la base y el punto de referencia de las diferentes manifestaciones en que se proyectan los demás derechos fundamentales y las libertades públicas. De forma que sin libertad de asociación o con un asociacionismo supeditado en todas sus manifestaciones al poder público, no hay democracia ni sistema de derechos y libertades ${ }^{8}$.

El artículo 22.1 CE reconoce el derecho fundamental de asociación, regulando, de forma general, el régimen aplicable a las diferentes modalida-

\footnotetext{
${ }^{7}$ Podemos citar, por lo que se refiere al reconocimiento genérico de la titularidad de los derechos fundamentales por parte de las personas jurídicas, tanto públicas como privadas, la STC 4/1982, de 8 de febrero (F.J. 5; ponente: D. Ángel Escudero del Corral) o la STC 64/1988, de 12 de abril, (ponente: D. Luis Díez-Picazo y Ponce de León) en la que se afirma que, aun cuando los derechos fundamentales son derechos individuales, se pueden reconocer excepciones «pues diferentes circunstancias pueden determinar que sean titulares de derechos fundamentales no sólo los individuos aisladamente considerados, sino también los grupos y organizaciones [...] incluyendo a las personas jurídicas, tanto a las de Derecho Privado como las de Derecho Público» (F.J.1).

${ }^{8}$ Fernández FARReres, Germán: Asociaciones y Constitución. Estudio específico del artículo 22 de la Constitución, Ed. Civitas, Madrid 1987, p. 17.

En el mismo sentido, el Tribunal Constitucional afirma que el artículo $22 \mathrm{CE}$ es uno de los elementos estructurales básicos del Estado social y democrático de Derecho (STC 173/1998, de 23 de julio, ponente: D. Carles Viver Pi-Sunyer, F.J. 8).
} 
des asociativas. Sin embargo, este precepto no precisa cuáles son las personas que pueden resultar titulares de este derecho, por lo que la discusión sobre la extensión de dicha titularidad también a las personas jurídicas, tanto públicas como privadas, ha sido una cuestión de especial interés tanto por la doctrina como por la jurisprudencia.

De esta manera, a pesar de que podemos afirmar que la mayoría de la doctrina reconoce la posibilidad de extender la titularidad del derecho de asociación no sólo a las personas físicas sino también a cualquier grupo o colectivo, esté dotado o no de personalidad jurídica ${ }^{9}$, cuando dicha extensión se refiere a las personas jurídico-públicas en general, la cuestión no resulta del todo clara.

En nuestra opinión, sin perjuicio de la indefinición del artículo $22 \mathrm{CE}$, a lo largo de nuestro ordenamiento jurídico podemos encontrar diferentes elementos que pueden ayudarnos a sostener una opinión favorable respecto a la posible extensión de la libertad de asociación también a los entes locales. Dichos elementos, a los efectos de una clara exposición, podemos agruparlos en cuatro categorías.

\section{a) La Carta Europea de la Autonomía Local}

En primer lugar, podemos partir de la Carta Europea de la Autonomía Local de 1985 (en adelante CEAL), ratificada por España el 20 de enero de 1988. La CEAL se configura como un tratado internacional válidamente celebrado y ratificado por el Estado español, por lo que, en atención al artículo 96.1 $\mathrm{CE}$, se integra en el ordenamiento jurídico español, adquiriendo rango de ley.

Con carácter general, la CEAL establece, a lo largo de sus 18 artículos, el marco o los principios fundamentales que deben regir el alcance de la autonomía local, protegiendo la representatividad democrática y los intereses competenciales y financieros de los entes locales.

Desde esta perspectiva, debemos tener presente que el artículo 10.2 CE obliga a interpretar las normas relativas a los derechos fundamentales y libertades públicas de conformidad con los tratados y acuerdos internacionales ratificados por España, por lo que, a la hora de determinar el contenido del derecho de asociación y su posible extensión a las entidades locales, las previsiones contenidas en la CEAL deben constituir un elemento interpreta-

\footnotetext{
${ }^{9}$ Véase, por ejemplo, LuCAs Murillo de la CuEva, Enrique: Igualdad y autonomía. Las competencias sobre asociaciones en la jurisprudencia constitucional, Ed. Civitas, Madrid 1999, p. 108-110 o VIDAL MARín, Tomás: «El derecho de asociación» en Parlamento y Constitución. Anuario, núm. 2, 1998, p. 205.

De forma similar, el Tribunal Constitucional, en la STC 64/1988, de 12 de abril (ponente: D. Luis DíezPicazo y Ponce de León), señala que el derecho de asociación lo pueden ejercer no sólo los individuos que se asocian, sino también las asociaciones ya constituidas (F.J. 1).
} 
tivo importante, en cuanto, en su tarea de garantizar la autonomía local, incide en una serie de derechos de los que son titulares las entidades locales, entre ellos el derecho de asociación.

En este sentido, el artículo 3 de la CEAL proclama y define el concepto de autonomía local, reconociendo a los entes locales el derecho y la capacidad para gestionar una parte importante de los asuntos públicos, bajo su propia responsabilidad y en beneficio de sus habitantes.

Así, la autonomía local se configura como una autonomía de carácter político, para ordenar una parte sustancial de los asuntos públicos mediante el impulso de políticas propias. Permitiéndoles, al mismo tiempo, determinar aquellas estructuras administrativas propias que les resulten más adecuadas para ello (art. 6.1 CEAL).

Por su parte, el artículo 10.1 de la CEAL reconoce expresamente el derecho de asociación de los entes locales, cuando afirma que dichas entidades «tienen derecho, en el ejercicio de sus competencias, de cooperar y, en el ámbito de la ley, asociarse con otras entidades locales para la realización de tareas de interés común».

Por lo tanto, y a partir de las previsiones anteriores, podemos considerar que la CEAL se expresa en términos suficientemente claros cuando reconoce el derecho de las entidades locales de establecer los medios de cooperación voluntaria y de asociación entre sí para la realización de tareas de interés común que consideren más adecuados, dentro del respeto al resto del ordenamiento jurídico. De esta manera, pues, la interpretación del artículo 22 $\mathrm{CE}$ debe tender a admitir el fenómeno asociativo local.

\section{b) El reconocimiento implícito: el principio de autonomía local}

Con carácter complementario al anterior, debemos tener también en cuenta el principio de autonomía local, regulado principalmente en el artículo 137 CE. Así, uno de los ámbitos en que, tradicionalmente, se ha venido concretando este principio es la llamada «potestad de autoorganización», que consiste en la facultad que se atribuye a determinados entes locales, para poder configurar su propia estructura interna. Es decir, la capacidad de dotarse de la organización que les resulte más adecuada para la gestión eficaz de sus respectivos intereses ${ }^{10}$.

\footnotetext{
${ }^{10}$ La potestad de autoorganización de los entes locales ha encontrado también un reconocimiento legal específico en los diferentes textos normativos que disciplinan el régimen local. Podemos citar, por ejemplo, el artículo 6.1 de la CEAL que dispone: «Sin perjuicio de las disposiciones más generales creadas por la Ley, las entidades locales deben poder definir por sí mismas las estructuras administrativas internas con las que pretenden dotarse, con objeto de adaptarlas a sus necesidades específicas y a fin de permitir una gestión eficaz».
} 
NUEVAS FORMAS DE COOPERACIÓN TERRITORIAL

La potestad de autoorganización constituye un elemento esencial de la autonomía local, puesto que parece imposible concebir un régimen de autonomía que merezca tal calificación sin reconocer a la comunidad o comunidades implicadas la posibilidad de establecer las bases de su administración. De este modo, se afirma que la autoorganización constituye no sólo un prius sino, a la vez, un atributo lógico del propio concepto de autonomía ${ }^{11}$.

Ahora bien, esta potestad de autoorganización no se agota solamente en la posibilidad de configurar la propia estructura interna, sino que supone también la posibilidad de determinar aquellos criterios y normas de funcionamiento que mejor se adapten a los intereses y necesidades de cada ente en particular. Pudiendo, asimismo, acudir a los diferentes mecanismos de cooperación y asociación con otras entidades locales que, para el cumplimiento de las finalidades públicas de interés común, se prevén en la legislación vigente.

En este sentido, el Tribunal Supremo, en la STS de 8 de abril de 1987, declara que dentro del ámbito de potestades de las corporaciones locales se encuentra la de autoorganización, que les permite crear «los órganos que consideren adecuados para el mejor funcionamiento de los servicios y cumplimiento de sus fines propios» (F.J. 2).

Por su parte, el profesor Luciano PAREJo destaca también esta posibilidad cuando señala que la potestad de autoorganización de los entes locales comprende no sólo el poder de determinar y configurar su estructura de gobierno y administración, tanto directa como indirecta o instrumental, sino también la posibilidad de articular la intervención local en la vida económica y codeterminar, junto con otras Administraciones públicas, las estructuras derivadas de la cooperación en el ámbito de las tareas comunes o compartidas entre diferentes entes locales ${ }^{12}$.

Por su parte, la Ley de Bases de Régimen Local (en adelante LBRL), en el artículo 4.1, prevé que las Administraciones públicas de carácter territorial y dentro de éstas, en todo caso los municipios, provincias e islas, deben disfrutar, entre otras, de la potestad de autoorganización, mientras que en los artículos 4.2 y 4.3 LBRL se hacen extensivas estas potestades a otros tipos de entidades locales.

En el ámbito catalán, el artículo 8.3 TrLM prevé que las potestades y prerrogativas previstas para las entidades locales territoriales (entre las que se encuentra la potestad reglamentaria y de autoorganización) son también aplicables a los otros entes locales no territoriales de acuerdo con lo que establezcan sus estatutos.

${ }^{11}$ Martín Mateo, Ramón: «El Gobierno municipal» en Revista de Estudios de la Administración Local y Autonómica, núm. 227, 1985, p. 425. En términos similares, FERnÁNDEZ FARRERES, Germán: «La potestad local de autoorganización» en MuÑoz MACHADO, Santiago (Dir.): Tratado de Derecho Municipal, volumen 1, Ed. Thomson Civitas, Madrid 2003, p. 1068.

${ }^{12}$ Parejo Alfonso, Luciano: «La potestad de autoorganización de la Administración Local» en Documentación Administrativa, núm. 228, octubre - diciembre 1991, p. 15-16.

Por su parte, Tomás FonT afirma: «[...] la Carta Europea da cobertura a una interpretación de la potestad de autoorganización municipal —específica expresión de la capacidad ordenadora y reguladoracon una decidida proyección de su contenido relacional externo, puesto que la capacidad de ordenar 
Por lo tanto, en el ámbito de las asociaciones de entidades locales, el contenido esencial de la potestad de autoorganización se manifiesta en la adopción por cada entidad local interesada, de forma autónoma y bajo su exclusiva responsabilidad, de la decisión inicial de articular, en el ejercicio de sus propias competencias y a través del acuerdo asociativo entre diferentes entidades locales, una nueva organización jurídicamente independiente a la que se atribuye el ejercicio de determinadas funciones relativas a la promoción y defensa de los intereses comunes y específicos de sus miembros.

\section{c) El principio de cooperación interadministrativa}

Al margen del principio de autonomía local al que acabamos de hacer referencia, podemos señalar también como fundamento de la libertad asociativa de los entes locales el principio de cooperación que debe presidir las relaciones interadministrativas.

El artículo 103.1 CE impone a las Administraciones Públicas el deber de actuar con eficacia, lo que supone, tal y como ha señalado en varias ocasiones el Tribunal Constitucional, la necesidad que las diferentes Administraciones Públicas armonicen el ejercicio de sus respectivas competencias, mediante el establecimiento de mecanismos de relación entre ellas que les permitan el ejercicio racional de sus funciones ${ }^{13}$.

Así, aun cuando no exista una previsión constitucional expresa que establezca la necesidad de prever mecanismos de cooperación entre las distintas entidades territoriales, el Tribunal Constitucional ha hecho referencia al deber general de colaboración interadministrativa, señalando que «dicho deber no es menester justificarlo en preceptos concretos, pues se encuentra implícito en la propia esencia de la forma de organización territorial del Estado que se implanta en la Constitución» (STC 18/1982, de 4 de mayo, ponente: D. Ángel Escudero del Corral, F.J. 14)

En términos similares, la Ley 30/1992, de 26 de noviembre, de Régimen Jurídico de las Administraciones Públicas y del Procedimiento Administrativo Común (en adelante LRJPAC), en su artículo 3.2, prevé expresamente que las relaciones entre Administraciones públicas deben regirse por los principios de cooperación y colaboración.

una parte importante de los asuntos públicos no debe encontrar limitaciones instrumentales en los medios organizativos, restringiéndose a los internos; antes al contrario, autonomía y autoorganización incluyen la necesaria proyección exterior mediante las relaciones de cooperación con otros entes locales y sus propios medios instrumentales». Véase FonT LlOVET, Tomás: «La reconstrucción jurídica de la autonomía local: el gobierno local y la reforma de los estatutos» en Font Llovet, Tomás (Dir.): Anuario del Gobierno Local 2003, Ed. Fundación Democracia y Gobierno Local - Instituto de Derecho Público, Barcelona 2004, p. 33.

${ }^{13}$ Por ejemplo, la STC 27/1987, de 27 de febrero (ponente: D. Gloria Begué Cantón), F.J. 2. 
NUEVAS FORMAS DE COOPERACIÓN TERRITORIAL

De este modo, las asociaciones de entes locales, creadas de común acuerdo y sobre la libre voluntad asociativa de sus miembros, se presentan como uno de los posibles mecanismos para articular dicha cooperación. Así, por medio de sus funciones de participación y consulta en órganos autonómicos o estatales, dichas asociaciones podrían constituirse como un instrumento muy útil dirigido a la articulación de un marco jurídico que permitiese el ejercicio ordenado y eficaz de las funciones reconocidas a las distintas entidades públicas, conjugando los principios de autonomía, unidad y solidaridad que reconoce nuestro texto constitucional.

\section{d) El reconocimiento legal: la Ley orgánica reguladora del derecho de asociación}

Finalmente, debemos señalar que el legislador postconstitucional español ha reconocido la titularidad del derecho de asociación no sólo a las personas físicas y jurídicas privadas sino también a las personas jurídico-públicas. Recogiendo de forma expresa esta posibilidad a lo largo del articulado de la reciente Ley Orgánica 1/2002, de 22 de marzo, reguladora del Derecho de asociación (en adelante LODA).

En este sentido, el artículo 2 LODA, al regular el contenido y los principios generales que deben regir el derecho de asociación, establece que todas las personas, en general, tienen derecho a asociarse libremente para la consecución de finalidades lícitas. El artículo 2.6 LODA se ocupa de concretar este alcance, señalando que «las entidades públicas podrán ejercitar el derecho de asociación entre sí o con particulares [...]».

Por su parte, el artículo 3 LODA, al referirse a la capacidad para el ejercicio del derecho de asociación, añade que «pueden constituir asociaciones, y formar parte de las mismas, las personas físicas y las personas jurídicas, sean estas públicas o privadas».

Por último, debemos mencionar que este reconocimiento expreso se ha producido también en el ordenamiento jurídico de Cataluña. Así, el Parlamento catalán, haciendo uso de la competencia atribuida por el artículo 9.24 del vigente Estatuto de Autonomía de Cataluña, procedió a aprobar la Ley 7/1997, de 18 de junio, de asociaciones (en adelante LCA). Esta Ley, que tiene por objeto la regulación jurídica y el fomento de las asociaciones que tengan su domicilio y desarrollen sus actividades principalmente en Cataluña, señala en su artículo 4 que pueden constituir asociaciones y ser miembros de las mismas, entre otras, las personas jurídicas, tanto públicas como privadas ${ }^{14}$.

\footnotetext{
${ }^{14}$ En el mismo sentido, el artículo 5 de la Ley 3/1988, de 12 de febrero, de Asociaciones del País Vasco, dispone que pueden constituir y ser miembros de las asociaciones: «b) las personas jurídicas de toda índole, públicas o privadas».
} 


\section{La peculiar naturaleza de las organizaciones asociativas de entes locales}

A pesar del reconocimiento genérico de la libertad asociativa de los entes locales al que acabamos de hacer referencia, la determinación de su concreto régimen jurídico debe articularse a partir de algunas consideraciones previas.

Ha sido el Tribunal Constitucional, como intérprete máximo de la CE, el que ha venido configurando el contenido esencial del derecho de asociación y, en la Sentencia 67/1985, de 24 de mayo (ponente: D. Rafael Gómez-Ferrer Morant), matiza que «el derecho de asociación reconocido en el artículo 22 no comprende el de constituir asociaciones cuyo objeto sea el ejercicio de funciones públicas de carácter administrativo relativas a un sector de la vida social. Esta posibilidad no se encuentra excluida por el artículo mencionado, cuyo número 3 se refiere a las asociaciones constituidas al amparo de este artículo, de donde se deduce a sensu contrario que no se excluye la existencia de asociaciones que no se constituyan a su amparo» (F.J. 3).

Por lo tanto, según el Tribunal Constitucional existen diferentes tipos de asociaciones que, a consecuencia del ejercicio de determinadas funciones públicas o por la relevancia que se otorga a los fines sociales, van más allá de las exigencias que impone el propio artículo $22 \mathrm{CE}$. De esta manera, se permite al legislador ordinario configurar el régimen jurídico particular de éstas, pudiendo establecer ciertos condicionantes específicos en relación con su constitución, organización y funcionamiento.

Ahora bien, esto no supone que el artículo 22 CE no les resulte aplicable y que su creación, organización y funcionamiento se desarrolle al margen de este precepto constitucional, sino que hemos de entender que, además de las previsiones fijadas por dicho artículo, deberán cumplir una serie de requisitos adicionales fijados por la legislación que les resulte singularmente aplicable ${ }^{15}$.

Es precisamente en este ámbito en el que debemos situar las asociaciones de entes locales. Las cuales, aun cuando inicialmente se podrían calificar como organizaciones de Derecho privado, asumen como actividad propia la participación en la consecución de finalidades públicas o de interés general ${ }^{16}$.

\footnotetext{
${ }^{15}$ Esteve Pardo, José: «Las asociaciones de configuración legal. El caso de las federaciones deportivas» en Civitas. Revista Española de Derecho Administrativo, núm. 45, 1985, p. 114. Opinión que es compartida también por Germán Fernández FARRERES, según el cual este régimen jurídico particular deberá respetar el núcleo o contenido esencial del derecho de asociación, en cuanto éstas no dejan de ser auténticos entes asociativos que entran dentro del ámbito de aplicación del artículo 22 CE. FERNÁNDeZ FarReres, Germán: Asociaciones y Constitución... Op. Cit., p. 157 y 204.

${ }^{16}$ Sobre la idea de participación y su traducción en el ámbito de la autonomía local, véase FonT LLOVET, Tomás: «Algunas funciones de la idea de participación» en Civitas. Revista Española de Derecho Administrativo, núm. 45, enero-mayo 1985, p. 45-53.
} 
Como hemos mencionado anteriormente, las asociaciones de entidades locales constituyen un mecanismo esencial para articular la representación de los intereses particulares de las entidades locales ante otras instancias territoriales superiores, tanto estatales como autonómicas. Así, la posibilidad de crear estas asociaciones puede verse como una manifestación de la autonomía local, entendida como el derecho de la comunidad local a participar a través de los órganos propios en los asuntos que les afecten. Es decir, como el derecho a participar en la gestión de una parte importante de los asuntos públicos.

En este punto, debemos recordar solamente lo previsto en el artículo 133.4 TrLM que afirma que las entidades asociativas de entes locales de Cataluña constituidas válidamente tendrán, para las instituciones de la Generalidad de Cataluña, la consideración de representantes de los intereses generales de las instituciones de gobierno local que agrupan. Y el artículo 133.5 TrLM añade que, para el cumplimiento de sus finalidades, las organizaciones asociativas de entes locales tienen derecho a participar en los órganos de la Administración de la Generalidad correspondientes.

De este modo, tanto por su composición (entidades públicas de carácter local), como por sus funciones esenciales (promoción y defensa de los intereses locales), así como por la posibilidad de integrarse en órganos colegiados consultivos o de deliberación, de carácter estatal o autonómico, es evidente que estas organizaciones asociativas de entes locales desarrollan actividades y funciones de naturaleza pública ${ }^{17}$. En consecuencia, se permite que el legislador pueda delimitar, de manera singular, el régimen jurídico al que deben someterse, estableciendo requisitos adicionales a los que se prevén, a todos los efectos, en el artículo $22 \mathrm{CE}$.

\section{EL MARCO NORMATIVO, EN ESPECIAL EN CATALUÑA}

Una vez examinado cuál es el fundamento jurídico al que podemos reconducir la libertad asociativa de los entes locales, debemos pasar ahora a analizar cuál ha sido el desarrollo normativo que se ha dado a ésta figura. Centrando nuestro específico objeto de estudio en el ámbito de la Comunidad Autónoma de Cataluña.

Podemos empezar diciendo que, hoy en día, la normativa legal vigente en el ordenamiento jurídico español relativa a estas formas asociativas es escasa y de carácter fragmentario, ya que no existe una norma que, con carácter general, establezca su régimen jurídico.

A estos efectos, podemos citar en primero lugar el artículo 10 CEAL, al que antes hemos hecho referencia y que contiene el reconocimiento genéri-

17 Rodríguez Álvarez, José Luis: Las Asociaciones...Op.Cit., pp. 34 y 151-153. 
co del derecho de asociación de las entidades locales. En el apartado 2 de este artículo 10 CEAL, se establece que «el derecho de las entidades locales de integrarse en una asociación para la protección y promoción de sus intereses comunes y el de integrarse en una asociación internacional de entidades locales deben ser reconocidos por cada Estado».

En este sentido, el legislador estatal ha reconocido esta posibilidad de asociación en la disposición adicional quinta de la LBRL ${ }^{18}$, que prevé:

«1. Las entidades locales pueden constituir asociaciones, de ámbito estatal o autonómico, para la protección y promoción de sus intereses comunes, a las que se aplicará su normativa específica y, en lo no previsto en ella, la legislación del Estado en materia de asociaciones.

2. Las asociaciones de Entidades locales se regirán por sus Estatutos aprobados por los representantes de las Entidades asociadas, los cuales deberán garantizar la participación de sus miembros en las tareas asociativas y la representatividad de sus órganos de gobierno. Asimismo se señalará en los estatutos la periodicidad con la que hayan de celebrarse las Asambleas Generales Ordinarias, en el caso que dicha periodicidad sea superior a la prevista, con carácter general, en el articulo 11.3 de la Ley Orgánica 1/2002, de 22 de marzo, reguladora del derecho de asociación.

3. Dichas asociaciones, en el ámbito propio de sus funciones, podrán celebrar convenios con las distintas administraciones públicas».

Esta normativa específica a la que se refiere la LBRL, como ya hemos mencionado, actualmente no existe. Si bien es cierto que la legislación sectorial que incide, aunque sea de forma parcial, sobre esta figura es bastante numerosa, al preverse, como hemos apuntado anteriormente, la participación de estas entidades asociativas en múltiples instancias consultivas y de cooperación. Sin embargo, algunas Comunidades Autónomas, entre ellas Cataluña, sí que han procedido a desarrollar, de una manera más o menos detallada y completa, el régimen jurídico de dichas instituciones.

La legislación catalana en este ámbito se articula sobre la base de dos normas principales: en primer lugar, el citado TrLM, aprobado por el Real Decreto Legislativo $2 / 2003$, de 28 de abril, que dedica su Título XI a regular «las organizaciones asociativas de entes locales».

En este sentido, en su artículo 133.1, se afirma que «los entes locales pueden asociarse en organizaciones para proteger y promover sus intereses comunes», que tendrán personalidad y capacidad jurídica propia para cumplir sus fines.

La creación de estas asociaciones, según el artículo 133.3 del TrLM, se regirá por el acuerdo de creación de la misma, que debe ser adoptado por la

\footnotetext{
${ }^{18}$ Según la redacción dada por la Ley 57/2003, de 16 de diciembre, de medidas para la modernización del gobierno local.
} 
NUEVAS FORMAS DE COOPERACIÓN TERRITORIAL

totalidad de los entes locales interesados y que, a la vez, debe comportar la aprobación de los estatutos por los que se debe regir.

Sin embargo, y sin perjuicio de su personalidad jurídica, debemos tener presente que estas agrupaciones de entes locales no constituyen una nueva entidad pública local, es decir, no constituyen una nueva persona jurídicopública instrumental. Por lo que este derecho de asociación previsto por la ley municipal catalana debe diferenciarse del derecho que tanto la LBRL como el TrLM reconocen a determinadas entidades locales para asociarse entre sí para el cumplimiento de finalidades de interés común o para la gestión de determinados servicios públicos, creando así nuevas personas jurídicas de Derecho público (ya sean, por ejemplo, mancomunidades de municipios o consorcios locales).

Finalmente, debemos mencionar que el artículo 136 TrLM (en términos similares a la disposición adicional quinta de la LBRL) dispone que, en todo aquello no fijado por éste, deberá acudirse a la legislación general en materia de asociaciones. Dicha legislación general, principalmente, vendrá configurada por aquello previsto directamente por el artículo $22 \mathrm{CE}$ y por las normas dictadas en desarrollo de este: básicamente, la regulación contenida en la ya mencionada Ley Orgánica 1/2002, de 22 de marzo, reguladora del derecho de asociación y en la ley catalana sobre asociaciones de $1997^{19}$.

En segundo lugar, encontramos también el Decreto 110/1996, de 2 de abril, sobre las organizaciones asociativas de entidades locales de Cataluña y su registro (en adelante DOA), que concreta las previsiones generales del Título XI del texto refundido de la ley municipal catalana.

En este sentido, se señala de forma expresa que «los entes locales de Cataluña pueden constituir organizaciones asociativas para proteger y promover sus intereses comunes y genéricos». Estableciendo, asimismo, que estas asociaciones se regularán por sus estatutos y por aquello que se prevé en el TrLM, debiendo acudir, en los aspectos no fijados en esta normativa, a la legislación general sobre asociaciones (art. 1.1 y 3 DOA).

En el artículo 6.1 DOA se concretan cuáles son las entidades que pueden ser miembros de este tipo de asociaciones, señalándose las siguientes: los municipios, las comarcas y los entes locales enumerados en el artículo 2 de la Ley municipal catalana (es decir, las provincias, las entidades municipales descentralizadas, las entidades metropolitanas y las mancomunidades de municipios). Al mismo tiempo, se excluyen los organismos autónomos, las

\footnotetext{
${ }^{19}$ La aprobación de la LODA, que desarrolla los elementos esenciales del derecho fundamental de asociación, ha supuesto el establecimiento de unas condiciones básicas para el ejercicio del derecho de asociación, por lo que aquellos preceptos de la LCA que pudiesen entrar en contradicción con esta deberán considerarse no aplicables. En este sentido, véase LuCAs Murillo DE LA Cueva, Enrique: Igualdad y autonomía. Las competencias sobre asociaciones en la jurisprudencia constitucional, Ed. Civitas, Madrid 1999, pp. 133-134.
} 
sociedades mercantiles, los consorcios y otras formas de gestión de los entes locales, así como los entes dependientes o vinculados a los mismos.

\section{SOBRE LA POSIBILIDAD DE INTRODUCIR SUPUESTOS DE DIFERENCIACIÓN EN EL RÉGIMEN DE ORGANIZACIÓN Y FUNCIONAMIENTO}

Una vez hechas las anteriores consideraciones, podemos pasar ya a centrarnos en la cuestión planteada en el inicio de nuestra exposición. Es decir, intentar determinar, a partir del examen del régimen jurídico de las organizaciones asociativas de entes locales en Cataluña, si es posible establecer formas de diversidad en la organización y funcionamiento de dichas organizaciones. Planteándonos, asimismo, si es jurídicamente admisible la previsión de posiciones jurídicas diferenciadas o si, por el contrario, dicho ordenamiento impone la exigencia de uniformidad en el régimen jurídico-subjetivo aplicable a todos sus miembros.

Para poder responder a estas cuestiones, debemos partir del estudio del Título XI TrLM y del desarrollo reglamentario que ha efectuado el DOA. Desde esta perspectiva, podemos afirmar que, aunque estos textos no se pronuncian de forma expresa, contienen una serie de consideraciones generales sobre las que vamos a estructurar nuestra exposición.

\section{La potestad de las entidades locales para configurar el régimen jurídico interno de las organizaciones asociativas de entes locales: la libertad positiva de asociación}

Un primer elemento a tener en cuenta en nuestro análisis consiste precisamente en examinar cuál es la capacidad que tienen las entidades locales para fijar, a través de los estatutos sociales, el régimen de organización y funcionamiento de las organizaciones asociativas de entes locales.

Como señalábamos anteriormente, el reconocimiento constitucional del derecho de asociación supone, en todo caso, la atribución a sus titulares del derecho de crear y participar en asociaciones. A su vez, este derecho supone también la capacidad de determinar su organización interna, mediante la realización de todas aquellas actuaciones dirigidas a ordenar la subsistencia y capacidad de funcionamiento de la asociación, sin más injerencias que aquellas previstas expresamente por la CE y las leyes.

En este sentido, el Tribunal Constitucional, en la STC 104/1999, de 14 de junio (ponente: D. Rafael de Mendizábal Allende), afirma que «el reconocimiento constitucional del derecho de asociación supone así la confirmación 
NUEVAS FORMAS DE COOPERACIÓN TERRITORIAL

de la libertad que tienen los ciudadanos para fundar y participar en asociaciones. Ese derecho a asociarse se plasma, no sólo en la libre elección de los fines asociativos, sino también en la disponibilidad de organizarse libremente, sin otro tipo de condicionamientos que los dimanantes de los límites mismos que al efecto prevea el Ordenamiento jurídico» (F.J. 2).

Y, en la STC 218/1988, de 22 de noviembre (ponente: D. Ángel Latorre Segura), el Tribunal Constitucional afirma que «el derecho de asociación, reconocido en el art. 22 de la Constitución, comprende no sólo el derecho a asociarse, sino también el de establecer la propia organización del ente creado por el acto asociativo dentro del marco de la Constitución y de las leyes que, respetando el contenido esencial de tal derecho, lo desarrollen o lo regulan (art. 53.1)» (F.J.1).

Por lo tanto, la libertad de asociación se manifiesta no sólo en la libre elección de sus fines o en la elección de los socios, sino también en la posibilidad de organizarse libremente, sin más interferencias por parte de los poderes públicos que aquéllas previstas expresamente por el ordenamiento jurídico.

En el ámbito de las organizaciones asociativas de entes locales estas previsiones se concretan, como destaca el propio artículo 133.2 TrLM, mediante el reconocimiento a dichos entes de la capacidad para elaborar y aprobar los estatutos sociales que constituirán la norma jurídica esencial de la asociación, configurando sus aspectos orgánicos y funcionales.

Así, corresponde a los estatutos la determinación del régimen jurídico particular de la asociación, fijando, entre otros aspectos, el nombre y domicilio de la asociación, la determinación de las finalidades perseguidas, los derechos y obligaciones de sus miembros, la organización y funcionamiento, el régimen disciplinario y los recursos económicos, de acuerdo con aquello previsto en el pacto de creación (art. 134 TrLM y art. 8 DOA).

\section{Las limitaciones a la potestad de las entidades locales para configurar el régimen jurídico interno de las organizaciones asociativas de entes locales}

Pese a la potestad que tienen las diferentes entidades locales para configurar el régimen jurídico de organización y funcionamiento del ente asociativo creado a tal efecto, es evidente que esta facultad no es ilimitada, sino que los estatutos de dicha asociación deberán respetar el ordenamiento jurídico. En especial, el contenido esencial del derecho de asociación previsto en el artículo $22 \mathrm{CE}$, así como aquellas previsiones que, con carácter mínimo, impone el Título XI TrLM y las normas dictadas en su desarrollo. 
Además, como hemos señalado anteriormente, el artículo 136 TrLM, así como el artículo 5.2 LBRL, prevén expresamente que, en los aspectos no regulados por estas normas, se tendrá que acudir a la legislación general sobre asociaciones. Por lo tanto, los estatutos deberán respetar también aquellas determinaciones que, con carácter necesario, se contienen en la LODA (o, en su caso, en la LCA).

La citada STC 104/1999 así nos lo recuerda cuando afirma que el derecho de los ciudadanos para asociarse «se plasma, no sólo en la libre elección de los fines asociativos, sino también en la disponibilidad de organizarse libremente [...]. El primer límite intrínseco a este derecho lo marca el principio de legalidad en cuya virtud los estatutos sociales, como ejercicio de la potestad de autonomía deben acomodarse no sólo a la Constitución, sino también a las leyes que, respetando el contenido esencial de tal derecho lo desarrollan o lo regulan» (F. J. 2).

Así pues, a la vista de estas consideraciones, podemos pasar a analizar cuáles son las principales limitaciones que el ordenamiento jurídico impone a esta libertad y que nosotros vamos a agrupar bajo dos grandes apartados.

\subsection{La asociación como forma de colaboración}

Un primer elemento que nos conduce a interpretar de forma restrictiva la posibilidad de introducir supuestos de diferenciación en el régimen jurídicosubjetivo de las organizaciones asociativas de entes locales se desprende del propio concepto de asociación.

Para entender el alcance de estas afirmaciones debemos destacar que, aun cuando el texto constitucional no contiene una definición propia sobre qué debe entenderse por «asociación», consideramos que, de su regulación, se desprenden algunos elementos que necesariamente deben de incluirse en toda organización o agrupación de personas que quiera participar de la noción de asociación ${ }^{20}$.

Estos elementos pueden concretarse en las siguientes ideas:

- Unión voluntaria entre varias personas. Toda asociación supone la agrupación de una pluralidad de individuos, ya sean personas públicas o privadas, que adoptan la condición formal de miembros o socios, y que son titulares de los intereses comunes perseguidos por el grupo.

\footnotetext{
${ }^{20}$ González Pérez, Jesús y Fernández Farreres, Germán: Derecho de Asociación. Comentarios a la Ley Orgánica 1/2002, de 22 de marzo, Ed. Civitas, Serie «Derechos Fundamentales y Libertades Públicas», Madrid 2002, p. 177-180. En términos similares, GómEz MonToro, Ángel J: Asociación, Constitución, Ley. Sobre el contenido constitucional del Derecho de asociación, Centro de Estudios Políticos y Constitucionales, colección «Estudios Constitucionales», Madrid 2004, p. 91 y sigs.
} 
NUEVAS FORMAS DE COOPERACIÓN TERRITORIAL

Se afirma también que esta agrupación debe ser voluntaria, de manera que la asociación se configura como el ejercicio de un derecho de libertad. Así, las asociaciones sólo pueden ser creadas por la voluntad de aquéllos que desean formar parte de éstas, quedando fuera del concepto constitucional de asociación aquellas agrupaciones forzosas o de creación legal.

- Vínculo organizativo estable. Toda asociación presenta una voluntad de permanencia y estabilidad en el tiempo para la consecución y realización de las finalidades asociativas propuestas.

Esta voluntad de permanencia se plasma en una estructura organizativa propia y en el establecimiento de mecanismos específicos para la formación de la voluntad común de sus miembros.

- La persecución de una determinada finalidad asociativa. La unión de diferentes personas en una asociación se produce con una clara voluntad o propósito de consecución conjunta de unos determinados fines compartidos por todos los asociados.

Estos tres elementos se hallan presentes en las organizaciones asociativas de entes locales, en cuanto suponen una actividad compartida de diferentes personas, que ponen en común sus conocimientos, medios y actividades, con el fin de hacer posible la realización conjunta de un interés común a todas ellas.

Desde esta perspectiva, estas ideas nos ponen de manifiesto que, cuando hablamos de organizaciones asociativas de entes locales, como agrupaciones de base asociativa, nos encontramos en un ámbito de cooperación voluntaria, caracterizándose, por lo tanto, por la ausencia de subordinación jerárquica entre sus miembros. De manera que sus normas de funcionamiento y el régimen jurídico de la adopción de acuerdos, tendrá un carácter esencialmente horizontal, pues no se producen por la imposición de unas entidades sobre las otras, sino, en base a la libertad, al consenso y la voluntariedad.

Este elemento intencional ha sido puesto de manifiesto por el Tribunal Constitucional, en la STC 218/1988, de 22 de noviembre (ponente: D. Ángel Latorre Segura), cuando afirma que «la asociación crea no sólo un vínculo jurídico entre los socios, sino también una solidaridad moral basada en la confianza recíproca y en la adhesión a los fines asociativos» (F.J. 1) ${ }^{21}$.

El mencionado artículo 10.1 CEAL, al regular el derecho de asociación de las entidades locales, destaca también este elemento participativo y de cooperación, cuando afirma que las entidades locales tienen el derecho, en el ejercicio de sus competencias «de cooperar» y de asociarse con otras entidades locales «para la realización de tareas de interés común».

${ }^{21}$ López-Nieto Mallo, Francisco: La ordenación legal de las asociaciones, Ed. Dykinson, Madrid 2004, p. 65. 
De esta manera, la noción de cooperación para la obtención de una finalidad común debe guiar nuestra interpretación, concretándose en el reconocimiento a las diversas entidades locales asociadas de la posibilidad de participar y desarrollar las tareas asociativas que les sean propias. Puesto que, como venimos afirmando, el derecho de asociación no tendría sentido si, una vez incorporado al ente asociativo, no se pudiera participar de sus actividades.

\subsection{Principios estructurales: el carácter democrático}

El artículo 10 DOA contiene un principio general, de carácter estructural, relativo a la organización y funcionamiento de las organizaciones asociativas de entes locales. Esta previsión supone una restricción importante a la libertad de establecer libremente su estructura interna, facultad consustancial a todo tipo de asociaciones. Así, señala que «la organización y el funcionamiento de las asociaciones [organizaciones asociativas de entes locales] deben de ajustarse a los principios democráticos» ${ }^{22}$.

En primer lugar, debemos mencionar que la exigencia de una organización y funcionamiento democráticos, en el caso de las organizaciones asociativas de entes locales, está plenamente justificada tanto por el carácter jurídicopúblico de sus miembros, como por la naturaleza pública de las funciones que se le reconocen y que no se prevén para el resto de asociaciones. Así, como hemos afirmado anteriormente, su peculiar naturaleza autoriza al legislador a modular su concreto régimen jurídico y a someterlas a limitaciones singulares, diferentes de las exigidas por las asociaciones de régimen general.

Es decir, a pesar del principio de libertad positiva de asociación, al que antes hemos hecho referencia, el legislador, en ciertos casos, estaría legitimado para introducir el requisito de la democracia interna (que, debemos recordar, encuentra su fundamento en uno de los principales valores constitucionales del artículo 1.1 CE) en la regulación de ciertos tipos de asociaciones, la relevancia pública y social de las cuales es, como en nuestro caso, innegable ${ }^{23}$.

\footnotetext{
${ }_{22}$ Aun cuando el TrLM no hace referencia expresa a la organización y funcionamiento democráticos de las organizaciones asociativas de entes locales esta exigencia puede considerarse implícita, en cuanto el artículo 136 del mencionado texto refundido remite, en todo aquello no previsto, a la legislación general sobre asociaciones, respecto la cual podemos señalar que, tanto la LODA (art. 5) como la LCA (art. 2), prevén, de manera expresa, que la organización y el funcionamiento de las asociaciones deben tener carácter democrático.

${ }_{23}$ Bilbao Ubillos, Juan María: Libertad de asociación y derechos de los socios, Universidad de Valladolid, Valladolid 1997, p. 21. En el mismo sentido se expresan Pablo SALvador Coderch y Josep FERRER, cuando, al analizar si sería posible la existencia de asociaciones que se organizaran sin respetar el pluralismo democrático, afirman: «mantiene su vigencia la respuesta que dio hace casi veinte años [...] Gunther Teubner: la sujeción a un estatuto democrático debe imponerse a aquellas asociaciones que representan intereses sociales ante las instancias públicas, a fin de procurar la mayor autenticidad posible en esa representación. Por ello, la Constitución Española ordena la estructuración democrática
} 
En el mismo sentido, se señala que el principio democrático puede trasladarse al ámbito de las asociaciones privadas, en su dimensión estructural. Exigiendo una organización y unos procedimientos democráticos a determinadas entidades que, no siendo públicas, tienen una posición de especial relevancia social o política ${ }^{24}$.

Ahora bien, determinar cuál es el alcance de esta declaración es una tarea sumamente difícil, puesto que el concepto de democracia es una noción muy amplia y compleja, y respecto de la cual no existe una única definición, sino que el simple intento de formularla encontraría múltiples resistencias ${ }^{25}$.

Así, en un intento de delimitar esta noción de un modo más preciso, podemos partir de los pronunciamientos que, sobre esta materia, ha ido elaborando el propio Tribunal Constitucional.

En la STC 56/1995, de 6 de marzo, (ponente: D. Carles Viver Pi-Sunyer), el Tribunal Constitucional intenta dotar de contenido jurídico a esta declaración cuando, al analizar las formas de funcionamiento y organización que la CE exige a los partidos políticos, afirma que la democracia interna se plasma en «reglas que permitan la participación de los afiliados en la gestión y control de los órganos de gobierno y, en suma, y esto es lo aquí relevante, mediante el reconocimiento de unos derechos y atribuciones a los afiliados en orden a conseguir esa participación en la formación de la voluntad del partido» (F.J. 3).

Y continúa diciendo «la exigencia constitucional de organización y funcionamiento democráticos no sólo encierra una carga impuesta a los partidos, sino que al mismo tiempo se traduce en un derecho o un conjunto de derechos subjetivos y de facultades atribuidas a los afiliados respecto o frente al propio partido, tendentes a asegurar su participación en la toma de las decisiones y en el control del funcionamiento interno de los mismos» (F.J. 3).

\footnotetext{
a determinadas asociaciones o corporaciones representativas de intereses sociales, pero no, con carácter general, de todas las entidades constituidas al amparo de su artículo 22». SALvAdor CODERCH, Pablo y FERrer RIBA, Josep: Asociaciones, derechos fundamentales y autonomía privada, Ed. Civitas, Madrid 1997, pp. 132-133.

Debemos recordar también que Germán GONZÁlEZ FARREREs sostiene que, aun cuando en algunos casos la propia Constitución fija ya algunas exigencias específicas a determinados tipos singulares de asociación, esto no supone que el legislador quede completamente desapoderado para incorporar otras exigencias que, modulando los principios básicos del artículo $22 \mathrm{CE}$, puedan hacer más rigurosa la constitución de estas asociaciones. El fundamento de esta «pérdida de libertad», según este autor, se encontraría en el reconocimiento y atribución a éstas de una serie de facultades de especial significación. FERnÁndez Farreres, Germán: Asociaciones y Constitución...Op. Cit., p. 196.

${ }^{24}$ Aragón Reyes, Manuel: Constitución y democracia, Ed. Tecnos, Colección «Temas clave de la Constitución Española», Madrid, 1989, pp. 112-113.

25 Gallardo Moya, Rosario: «Derecho de asociación y exigencia de democracia interna de los partidos políticos (Comentario a la STC 56/1995, de 6 de marzo)», en Derecho Privado y Constitución, núm. 8, enero - abril, 1996, p. 240.
} 
Aún así, el máximo intérprete constitucional, en la citada sentencia, considera también que éste es un derecho de configuración legal, puesto que el principio de democracia interna admite desarrollos muy diversos. De esta manera «la concreción del legislador resulta, por tanto, absolutamente necesaria y en la realización de esta tarea goza, como queda dicho, de un amplío margen de configuración». Si bien el legislador deberá respetar el contenido esencial de participación democrática, así como el contenido de otros derechos con los que ésta guarda relación (por ejemplo, el derecho de libre creación o la libertad de autoorganización).

\subsubsection{La organización interna}

Como señala la citada STC 56/1995, el Tribunal Constitucional entiende que uno de los elementos que definen el carácter democrático de una organización asociativa es la idea de participación de sus miembros en su funcionamiento. De manera que su organización interna debe tender a integrar dentro de ésta a las diferentes personas asociadas, mediante el establecimiento de unos órganos y unos procedimientos que les permitan expresar, de forma efectiva y no meramente formal, su voluntad.

Desde este punto de vista, el DOA concreta, para las organizaciones asociativas de entes locales, una estructura organizativa determinada, a través de la cual se pretende asegurar la participación democrática de todas las entidades locales asociadas.

Por lo tanto, a pesar de la capacidad de los propios entes asociados para fijar, a través de los estatutos, aquellas formas de gobierno y administración que consideren más convenientes para cada supuesto particular, determinando, por ejemplo, cuál debe su composición, las reglas y los procedimientos para la elección y sustitución de sus miembros, sus atribuciones, la duración de su cargo, las causas de cese, así como la forma de deliberar, adoptar y ejecutar los acuerdos, se exige también, con carácter necesario, la existencia de unos determinados órganos de gobierno y administración de ésta, sin los cuales no podría inscribirse válidamente en el registro público correspondiente. Estos órganos son los siguientes:

\section{a) La asamblea general}

La asamblea general se configura como el órgano supremo de gobierno de la asociación, de carácter representativo, que debe estar integrada por todos los entes asociados (art. 11.2 DOA). La asamblea general pues, se presenta como el órgano máximo de deliberación y decisión de la organización, a la cual corresponde la adopción de aquellas decisiones con más trascendencia asociativa. 
En cuando a su composición, el DOA prevé que la asamblea general estará formada por los representantes de todas las entidades locales asociadas, sin que la eventual existencia de diferentes tipos de entes locales pueda dar lugar a la celebración de asambleas generales especiales, titulares de un derecho de veto colectivo sobre las decisiones de la asamblea general que les afecten de forma particular ${ }^{26}$.

Además, en el supuesto de que los estatutos sociales no dispongan otra cosa, los artículos 11 y 12 LODA prevén las normas básicas de su régimen jurídico interno, especialmente en lo que se refiere a la convocatoria de sesiones y a la adopción de acuerdos. Señalando que la asamblea general debe reunirse como mínimo una vez al año y que los acuerdos deberán adoptarse por mayoría simple de las personas presentes, exceptuando los acuerdos relativos a la disolución de la asociación, modificación de los estatutos, disposición y alienación de bienes y remuneración de los miembros del órgano de representación, que se adoptarán por mayoría cualificada.

\section{b) El órgano de representación de la asociación}

Junto con la asamblea general, es necesaria también la existencia de un órgano de representación de la asociación, encargado de gestionar y representar los intereses de ésta de acuerdo con las disposiciones y directrices de la asamblea general.

Aunque ni el TrLM ni el DOA hacen referencia expresa a este órgano, su existencia, en cierto modo, se presupone. Así, el artículo 11.1 DOA se refiere a los «órganos de gobierno y administración» de las asociaciones, por lo que este precepto refleja una clara voluntad de diferenciar aquello que corresponde al gobierno de la asociación, es decir, a la formación de la voluntad de la asociación, la cual se atribuye a la asamblea general, y las materias relativas a la gestión o administración ordinaria, la competencia de las cuales debe atribuirse a un órgano diferenciado, de carácter singular.

Esta diferenciación no es una característica propia de las organizaciones asociativas de entes locales, en cuanto, tanto el artículo 11.4 LODA como el artículo 12.2 de la LCA, establecen la necesidad de que en toda asociación exista un órgano de estas características, la previsión y regulación del cual se configura como uno de los requisitos mínimos que deben contenerse en los estatutos asociativos.

Además, su existencia se justifica también por razones de eficacia y de coherencia interna en el funcionamiento de la asociación. En este sentido, las asociaciones, como todas las personas jurídicas, necesitan de órganos singu-

${ }^{26}$ Cabanas Trejo, Ricardo: Comentario a la Ley catalana de Asociaciones, Ed. Marcial Pons, Madrid 2000, p. 189. 
lares capaces de ejecutar las decisiones tomadas por la asamblea general $(\mathrm{u}$ órgano equivalente), así como para llevar su gestión ordinaria ${ }^{27}$.

Este órgano de representación, que puede adoptar diferentes denominaciones (junta directiva, junta general, etc.), será el responsable legal y económico de la asociación, constituyéndose en el principal órgano de trabajo del ente asociativo. Responsabilizándose, asimismo, de todo aquello que se le delegue expresamente y de los temas que no hayan sido expresamente atribuidos a cualquier otro órgano.

Como en el caso anterior, su estructura, composición y funciones deberán ser regulados en los estatutos sociales. Si bien el artículo 11.4 LODA lo configura como un órgano colegiado, en el cual la participación se limita solamente a los entes locales asociados, escogidos por la asamblea general mediante un procedimiento basado en los principios de libertad de expresión y de proposición de candidaturas y de concesión de igualdad de oportunidades a los candidatos.

\section{c) El presidente}

Al margen de estos dos órganos, el artículo 15.3 DOA hace referencia a la existencia de un presidente de la asociación, al que se le encomienda la función de solicitar la inscripción de ésta en el Registro de organizaciones asociativas de entes locales de la Generalidad de Cataluña. Por lo tanto, su existencia se presupone como un requisito necesario para que, mediante la inscripción en el registro público correspondiente, la organización asociativa de entes locales constituida a tal efecto, pueda obtener la consideración, por parte de la Generalidad de Cataluña, de representante de los intereses de las instituciones de gobierno local que agrupa (art. 22.1 DOA).

Sin embargo, es evidente que los estatutos sociales podrían atribuirle otras funciones en atención a las características singulares de cada asociación (por ejemplo, la representación legal de la asociación o la dirección de las sesiones de la asamblea general, pudiendo decidir los empates con voto de calidad).

\section{d) Otros órganos}

Sin perjuicio de la existencia de estos órganos, la cual se presupone en todo caso necesaria, en uso de la libertad positiva de asociación, los estatutos sociales podrían prever también la existencia de otros órganos de naturaleza potestativa (por ejemplo, el establecimiento de una o más vicepresi-

${ }^{27}$ LóPeZ-Nieto y Mallo, Francisco: La ordenación legal... Op. Cit., p. 503. 
NUEVAS FORMAS DE COOPERACIÓN TERRITORIAL

dencias, la tesorería o la secretaría de la asociación), dejando a aquéllos la precisión de sus competencias y el alcance de sus atribuciones.

\subsubsection{Derechos de los entes asociados}

Como señalábamos anteriormente, junto con la organización interna, el Tribunal Constitucional ha considerado que la exigencia de un funcionamiento democrático debe suponer, a la vez, el otorgamiento a los entes asociados de una serie de derechos y facultades ante la propia organización, al efecto de asegurar su participación efectiva en ésta.

En primer lugar, debemos destacar que las normas reguladoras de las organizaciones asociativas de entes locales en Cataluña no prevén un catálogo de derechos que deban reconocerse, con carácter general, a todos sus miembros, dejando su concreta determinación a los estatutos de la asociación.

Así, el artículo 14 del DOA, establece que «los estatutos deberán de establecer el régimen de los derechos y deberes de los entes asociados, sin que se puedan prever derechos especiales ni cargas específicas para ningún miembro o grupo de miembros con ventaja o perjuicio para el resto, sin perjuicio de la ponderación en el voto y en las aportaciones, fundamentada en criterios objetivos».

\section{a) Desigualdad en el régimen jurídico subjetivo}

Desde esta perspectiva, uno de los primeros interrogantes que se nos plantea es determinar la posible introducción de supuestos de diferenciación dentro del régimen de los derechos y deberes de los entes locales asociados.

Para responder a esta cuestión y para poder valorar, en su caso, cuál es el ámbito y extensión que podemos dar a estos supuestos, es necesario partir de la consideración del principio de igualdad, en tanto que principio inspirador de nuestro sistema jurídico.

En este sentido, a pesar que el Tribunal Constitucional ha considerado que las Administraciones Públicas no son titulares del derecho fundamental a la igualdad reconocido en el artículo $14 \mathrm{CE}^{28}$, el máximo órgano constitucio-

\footnotetext{
${ }^{28}$ El Tribunal Constitucional, como ya hemos mencionado en el inicio de este trabajo, sólo reconoce a las Administraciones Públicas la titularidad de aquellos derechos fundamentales la naturaleza de los cuales así lo permita. Respecto al derecho a la igualdad reconocido en el artículo 14 CE, el Tribunal Constitucional ha adoptado una interpretación muy restrictiva, afirmando, que «nuestra jurisprudencia ha declarado que los entes públicos no pueden ser considerados como titulares del derecho fundamental a la no discriminación amparado por el artículo $14 C E$, que se refiere a los españoles, y no es de aplicación a las personas jurídico públicas en cuanto tales» (STC 211/1996, de 17 de diciembre, ponente: D. Álvaro Rodríguez Bereijo, F.J. 4).
} 
nal afirma también que la igualdad conforma uno de los valores superiores de nuestro ordenamiento jurídico, tal y como se prevé en el artículo 1.1 CE. Así, la igualdad constituye uno de los pilares básicos sobre los que se asienta nuestra sociedad y sobre los que se fundamenta el ordenamiento jurídico en su conjunto, actuando, junto al resto de valores superiores del ordenamiento jurídico, como punto de partida para la comprensión de las normas constitucionales y del resto de disposiciones dictadas en su desarrollo. Derivándose, por ello, la necesidad de que los poderes públicos adopten las medidas oportunas para conseguir su efectividad.

Según el Tribunal Constitucional, «la Constitución es una norma [...] pero una norma cualitativamente distinta a las demás por cuanto incorpora el sistema de valores esenciales que deben constituir el orden de convivencia política y de informar todo el ordenamiento jurídico» (STC 9/1981, de 31 de marzo, ponente: D. Rafael Gómez-Ferrer Morant, F.J. 3).

De esta manera, para que «la libertad, la justicia, la igualdad y el pluralismo político sean una realidad efectiva y no la enunciación teórica de unos principios ideales», es necesario que «a la hora de regular conductas y, por tanto, enjuiciarlas, se respeten aquellos valores superiores sin los cuales no se puede desarrollar el régimen democrático que nos hemos dado en la Constitución de 1978» (STC 20/1990, de 15 de febrero, ponente: D. Fernando García-Mon y González-Regueral, F.J. 3).

Por lo tanto, para el Tribunal Constitucional la igualdad es un valor preeminente de nuestro ordenamiento jurídico, la cual, «junto con otros valores integran la sustancia de un sistema democrático y libre», se proyecta «con una eficacia trascendente, de modo que toda desigualdad persistente a la entrada en vigor de la norma constitucional deviene incompatible con el orden de valores que la Constitución, como norma suprema, proclama» (STC 8/1983, de 18 de febrero, ponente: D. Jerónimo Arozamena Sierra, F.J. 3).

Es desde esta perspectiva que debemos proceder a interpretar el artículo 14 del DOA, el cual, a pesar de remitir a los estatutos asociativos la determinación concreta de los derechos y deberes de las partes, parece partir de la igualdad de todos los entes asociados, en cuanto establece que no se podrán prever «derechos especiales ni cargas específicas para ningún miembro o grupo de miembros». Ahora bien, podemos afirmar que, en este ámbito, la igualdad se entiende no como el reconocimiento a todos los entes locales asociados de los mismos derechos y deberes, sino como la prohibición de establecer desigualdades que puedan considerarse discriminatorias. De for-

\footnotetext{
Igualmente, en la STC 240/2001, de 18 de diciembre (ponente: D. Tomás S. Vives Antón), considera que las personas jurídico-públicas no pueden ser titulares del derecho a la igualdad previsto en el artículo $14 \mathrm{CE}$, puesto que este se fundamenta en la dignidad de la persona por lo que «no es trasladable a aquéllas [personas públicas], pues el artículo 14 CE se refiere a los ciudadanos y, en consecuencia, no es de aplicación a las personas jurídico públicas en cuanto tales» (F.J. 3).
} 
ma que el elemento clave del principio de igualdad radica no en la «no diferenciación» sino en la «no discriminación».

El propio artículo 14 DOA afirma que no pueden preverse derechos especiales o cargas específicas que «supongan una ventaja o perjuicio para el resto de miembros» por lo que, a sensu contrario, podemos entender que la introducción de diferentes posiciones jurídicas respecto a los derechos y los deberes de los entes asociados sería posible, pero únicamente en el supuesto de que éstas no causaran perjuicios o privilegios para el resto de miembros. Situaciones estas que podrían justificarse en conseguir un funcionamiento más racional de la organización, que permitiera acometer, de forma más eficiente, las finalidades perseguidas. De forma que la diferenciación puede ser, al mismo tiempo, expresión del valor de la igualdad.

Así lo ha entendido también el Tribunal Constitucional, según el cual el contenido del principio de igualdad no supone que todos los sujetos hayan de tener los mismos derechos y obligaciones, sino que implica únicamente una prohibición de discriminación. De tal manera que, ante situaciones iguales, deben darse tratamientos iguales. Así, sólo podrá alegarse la vulneración del principio de igualdad cuando, dándose los requisitos previos de igualdad entre los sujetos afectados, se produce un tratamiento diferenciado de éstos en atención a una conducta arbitraria o no justificada. Es decir, si la desigualdad carece de una justificación objetiva y razonable en atención a la finalidad y a los efectos que se persiguen ${ }^{29}$.

De esta manera pues, la única limitación que se impondría a la hora de introducir estos supuestos de diferenciación sería la previa existencia de una justificación objetiva, suficiente y razonable, de acuerdo con criterios y juicios de valor generalmente aceptados y siempre que sus consecuencias no resulten, en todo caso, desproporcionadas. En este sentido, el propio artículo 14 DOA señala ya dos posibles ámbitos en los que, ateniendo a circunstancias objetivas, se podrían establecer supuestos de diferenciación. Estos dos ámbitos son los relativos a la ponderación del voto y la diferenciación en las aportaciones económicas a realizar.

Debemos señalar también que, pese a la posibilidad de poder introducir supuestos de diferenciación en los derechos de las diferentes entidades locales, también se podría optar por la opción contraria, es decir, el establecimiento de un régimen de estricta igualdad entre los derechos de todos los entes aso-

\footnotetext{
${ }^{29}$ Podemos citar, por ejemplo, la STC 34/1981, de 10 de noviembre (ponente: D. Rafael Gómez-Ferrer Morant), en la que se establece que «[...] lo que prohíbe el principio de igualdad es la discriminación, como declara de forma expresa el art. $14 \mathrm{CE}$; es decir, que la desigualdad de tratamiento sea injustificada por no ser razonable» (F.J. 3). En el mismo sentido, la STC 49/1982, de 14 de julio (ponente: D. Luis Díez-Picazo y Ponce de León) señala que «la igualdad a la que el artículo 14 se refiere [...] no comporta necesariamente una igualdad material o igualdad económica real y efectiva. Significa que a los supuestos de hecho iguales deben serles aplicados consecuencias jurídicas que sean iguales también y que para introducir diferencias entre los supuestos de hecho tiene que existir suficiente justificación de tal diferencia, que aparezca al mismo tiempo como fundada y razonable de acuerdo con criterios y juicios de valor generalmente aceptados» (F.J. 2).
} 
ciados. Según el Tribunal Constitucional, ésta sería una situación perfectamente aceptable en cuanto el principio de igualdad sólo ampara el derecho a no sufrir discriminaciones o diferencias carentes de justificación objetiva o razonable, pero no ampara la falta de distinción entre supuestos desiguales.

Así se declara, por ejemplo, en la STC 86/1985, de 10 de julio (ponente: D. Francisco Rubio Llorente), en la que el Tribunal afirma que el principio de igualdad lo que impide es «la distinción infundada o discriminación [...], pero no la falta de distinción entre supuestos desiguales o discriminación por indiferenciación» (F.J. 3).

Y, de forma similar, la STC 52/1987, de 7 de mayo (ponente: D. Jesús Leguina Villa, F.J.3) y la STC 36/1999, de 22 de marzo, (ponente: D. Pablo Manuel Cachón Villar, F.J.4), prevén que el derecho reconocido en el artículo $14 \mathrm{CE}$ reconoce el derecho a no sufrir discriminaciones, pero no el hipotético derecho a imponer o exigir diferencias de trato.

\section{b) Los derechos de los entes locales asociados}

Una vez hechas las anteriores precisiones, hace falta preguntarse cuales son los concretos derechos que, con carácter mínimo, deben de reconocerse a los entes locales asociados. Estos derechos deben tener por objeto asegurarles su participación en el funcionamiento de la asociación y hacer efectivas las exigencias derivadas de la imposición del principio de democracia interna en la organización y funcionamiento de la asociación.

Como hemos dicho anteriormente, las normas reguladoras de las organizaciones asociativas de entes locales no prevén un catálogo general de derechos que deban reconocerse, a todos los efectos, a los miembros de éstas. Aún así, y a falta de una regulación más detallada, podemos acudir al artículo 21 LODA que prevé una serie de derechos que, con carácter mínimo, deben reconocerse a los miembros de toda asociación, entre los que encontramos:

1. Derechos políticos: El artículo 21 a) LODA prevé que todos los asociados tienen derecho a participar en las actividades de la asociación y en los órganos de gobierno y representación, a ejercer el derecho de voto, así como a asistir a la asamblea general, de acuerdo con los estatutos. Estos derechos pueden concretarse en los siguientes:

- Derecho a participar en las actividades de la asociación: Como ya hemos mencionado, el propio concepto de asociación hace ya referencia a la idea de colaboración y participación de las diferentes entidades que la conforman, por lo que todos los entes locales asociados deben tener derecho a participar en las actividades de ésta para la consecución de sus finalidades. 
Este derecho deberá desarrollarse en los estatutos sociales, que deberán concretar las diferentes formas de participación, destacando que, si bien no se puede negar a ningún socio el derecho a participar en las actividades de la asociación, sí que puede resultar aconsejable que los estatutos configuren esta posibilidad en atención a las capacidades y aptitudes de cada una de las entidades que, en particular, conforman la asociación. Teniendo en cuenta también que los criterios para establecer posibles desigualdades deben ser objetivos, racionales y proporcionales a la finalidad perseguida.

- Derecho a asistir a la asamblea general: Las diferentes entidades asociadas tienen derecho a asistir a la asamblea general, que, como hemos visto, es el órgano soberano de la asociación, formado por la agrupación de todos sus miembros.

El derecho de asistencia se configura como un derecho de carácter indisponible por los estatutos, por lo que su titularidad no podría modularse ni limitarse. Así, el artículo 11.2 DOA exige expresamente que la asamblea general debe estar integrada por los representantes de todos los entes asociados.

Por otro lado, este derecho supone también la posibilidad de intervenir activamente en las deliberaciones y, por lo tanto, el derecho a ser escuchado. Si bien el ejercicio del derecho de voz deberá ejercerse en atención a la regulación que los estatutos hayan previsto sobre la forma de desarrollar las sesiones.

- Derecho de voto: El derecho de voto constituye el principal derecho instrumental del socio, puesto que por medio de éste contribuye a conformar la voluntad de la asociación.

En principio, todo asociado debe poder disponer, como mínimo, de un voto en la asamblea general, si bien, como hemos señalado anteriormente, el artículo 14 del DOA prevé expresamente la posible existencia de mecanismos de ponderación del voto, es decir, el establecimiento de diferencias en el valor del voto de los diferentes miembros de la organización asociativa, aun cuando el propio artículo 14 DOA establece que estas desigualdades deberán fundamentarse en unos parámetros o criterios de carácter objetivo (por ejemplo, población, las aportaciones económicas realizadas, etc.) que hicieran posible eliminar cualquiera duda de arbitrariedad en el reparto de los votos.

Como señala CABAnas Trejo, el reparto de votos no necesariamente debe ser proporcional, sino que serían posible también sistemas regresivos (votos reforzados pero menos que proporcionales) y sistemas progresivos (votos más que proporcionales), siempre que éstos estuvieran perfectamente especificados en los estatutos y resultaran objetivos en atención a las características particulares de sus miembros ${ }^{30}$.

${ }^{30}$ Cabanas Trejo, Ricardo: Comentario...Op. Cit., pàg. 277. 
- Derecho a participar en los órganos de gobierno: Este derecho hace referencia a la posibilidad de ser elector, que se concreta en el reconocimiento del derecho de voto en la asamblea general, y en la posibilidad de resultar elegible para formar parte de los órganos de gobierno de la asociación, sin que sea posible introducir requisitos no objetivos que limiten este derecho.

2. Derechos de información: El artículo 21 b) LODA prevé que todos los socios tienen derecho a ser informados sobre la composición de los órganos de gobierno y representación de la asociación, de su estado de cuentas y del desarrollo de su actividad.

En nuestro ámbito de estudio, este derecho se concreta en la capacidad de las entidades locales asociadas a conocer la situación material y financiera de la asociación, para que, en el caso de que se constatara un funcionamiento irregular, se pudieran ejercer los mecanismos de defensa e impugnación correspondientes. Este derecho no podría condicionarse por los estatutos, si bien su ejercicio puede someterse a reglas de lugar, tiempo y for$\mathrm{ma}^{31}$.

Dentro de este derecho hace falta incluir el derecho de los asociados a acceder a toda la documentación y libros relativos al funcionamiento de la asociación. Además, este derecho no podría limitarse a que los órganos de gobierno y administración dieran traslado del contenido de los documentos a los distintos miembros, sino que comprende la posibilidad de acceder directamente a la documentación requerida ${ }^{32}$.

3. Garantías en los expedientes disciplinarios. Comprende el derecho a ser escuchado con carácter previo en la adopción de medidas disciplinarias y a ser informado de los hechos que dan lugar a estas medidas, así como la exigencia de motivación de la sanción.

En este punto, solamente recordar la STC 104/1999, de 14 de junio (ponente: D. Rafael de Mendizábal Allende), en la que se admite el control judicial sobre la imposición de las medidas disciplinarias respecto de los socios, si bien «su alcance no consiste en que el Juez pueda entrar a valorar, con independencia del juicio que ya hayan realizado los órganos de la asociación [...] sino comprobar si existió o no una base razonable para que aquellos tomasen la correspondiente decisión» (F.J. 3).

\footnotetext{
31 González Pérez, Jesús y Fernández Farreres, Germán: Derecho de asociación...Op. Cit., p. 294.

32 González Pérez, Jesús y Fernández Farreres, Germán: Derecho de asociación...Op. Cit., p. 295. En el mismo sentido, Cabanas Trejo, Ricardo: Comentario...Op. Cit., p. 285, cuando afirma que el asociado tiene derecho a consultar, directamente, los libros de la asociación.
} 
NUEVAS FORMAS DE COOPERACIÓN TERRITORIAL

\section{CONCLUSIÓN}

El desarrollo de nuestro complejo modelo de organización territorial del Estado ha provocado que las relaciones de cooperación entre las distintas entidades públicas se configuren como un fenómeno necesario para el cumplimiento de sus finalidades públicas. Dichas relaciones contribuyen a hacer posible un ejercicio racional de las competencias públicas, haciendo compatibles los principios de eficacia y eficiencia que nuestro texto constitucional propugna.

En el caso de las Administraciones públicas locales, la cooperación territorial constituye un nuevo mecanismo para afrontar de una manera más decidida y eficaz los nuevos retos que la sociedad actual les impone. Aprovechando, así, complementariedades funcionales entre los diferentes tipos de entes locales y garantizando la adopción de medidas conjuntas en la defensa y promoción de sus intereses comunes.

En este sentido, pese a la escasa cultura de cooperación local existente en el Estado español, nuestro ordenamiento jurídico pone a disposición de estos entes una serie de mecanismos de cooperación interadministrativa. De entre todos estos mecanismos, uno de los más singulares es el constituido por las denominadas asociaciones de entes locales.

Estas asociaciones, como apuntábamos, no se constituyen para la prestación en común de determinados servicios públicos, sino para ejercer actividades dirigidas al fomento de la autonomía local, participando y representando los intereses de sus miembros ante de los niveles superiores de gobierno. Facilitando, de esta manera, el estudio y difusión de sus necesidades específicas y de los problemas que les afectan.

Este tipo de organizaciones asociativas encuentra su origen en el derecho de asociación reconocido en el artículo $22 \mathrm{CE}$, derecho que la CEAL y la LODA se encargan de extender también a las entidades públicas locales.

Además, su carácter asociativo y voluntario se manifiesta también en la capacidad de las entidades locales no sólo para poder constituir este tipo de asociaciones para la promoción y defensa de sus intereses comunes y específicos, sino también para determinar su régimen jurídico interno, a través de la aprobación de los correspondientes estatutos asociativos, que deberán configurar su régimen orgánico y de funcionamiento.

Ahora bien, desde nuestro punto de vista, hemos afirmado que estas asociaciones reúnen también una evidente naturaleza pública, puesto que, tanto desde un punto de vista subjetivo (están formadas por entes públicos locales de carácter territorial) como por sus finalidades específicas (la representación de los intereses particulares de estas entidades y la participación formal en otras instancias políticas territoriales), presentan elementos singulares que las configuran como un tipo especial de asociación. 
En este sentido, la LBRL determina, con carácter general, su régimen jurídico particular, a la vez que el TrLM y el DOA concretan dichas previsiones normativas para el ámbito territorial de Cataluña.

Estas normas, introducen límites y exigencias singulares, dirigidas a preservar, precisamente, la naturaleza cooperativa de esta institución y dirigidas a asegurar la participación de las diferentes entidades asociadas en su funcionamiento, destacando la exigencia de que su organización y funcionamiento sean democráticos.

A pesar de la evidente indefinición de esta exigencia, partiendo de la interpretación que el Tribunal Constitucional ha realizado en el ámbito de los partidos políticos, podemos llegar a la conclusión que la configuración interna de la asociación debe suponer, como mínimo, el reconocimiento a todas las entidades asociadas de la posibilidad de participar en el funcionamiento de la misma. Exigiéndose, de este modo, no sólo una determinada estructura orgánica, sino también la previsión de una serie de derechos propios que hagan efectiva esta participación.

Por lo que se refiere a su organización interna, el DOA se ocupa de prever cuáles deben ser los órganos que, con carácter necesario, deben de existir en las organizaciones asociativas de entes locales. Así, se afirma que éstas estarán integradas por una asamblea general, representativa de todos los entes asociados, sin distinción de clases o categorías, y un órgano colegiado de administración y representación de la asociación, encargado de la gestión ordinaria de la misma.

Al mismo tiempo, se prevé la existencia de un presidente, al cual se le encarga, como mínimo, la inscripción de la asociación en el registro correspondiente, al efecto que esta pueda tener la consideración, para las instituciones de la Generalidad de Cataluña, de entidad representativa de los intereses de las instituciones de gobierno local que agrupa.

Por otro lado, por lo que se refiere al régimen de los derechos y deberes de los entes locales asociados, aun cuando la normativa local aplicable no establece un catálogo general de derechos, debemos tener presente que el artículo 14 DOA parte de la igualdad de derechos entre los diferentes entes asociados. Así, se impide que los estatutos asociativos puedan introducir derechos especiales o cargas específicas, que supongan una ventaja o un perjuicio para el resto de miembros, debiendo reconocerse a éstos el derecho a impulsar el cumplimiento de las finalidades asociativas, a través de la dedicación voluntaria a ésta y la aportación de las contribuciones económicas pertinentes, así como la participación en la gestión y control de los órganos de gobierno y administración.

Aún así, como afirmábamos y siguiendo los razonamientos que el Tribunal Constitucional ha ido elaborando en atención al principio de igualdad, no 
se excluye la posibilidad de que los estatutos sociales puedan incluir aquellas modulaciones en el régimen jurídico de organización y funcionamiento que resulten más necesarias y que se justifiquen debidamente en razones objetivas, suficientes y razonables.

Finalmente, queremos acabar nuestra exposición poniendo nuevamente de manifiesto que las organizaciones asociativas de entes locales, por su flexibilidad en cuanto a los contenidos, por su carácter dinámico en cuanto a la definición y solución de problemas, así como por el hecho que constituyen una herramienta capaz de generar la confianza y los consensos necesarios para la interacción entre los diferentes actores públicos locales, pueden presentarse como un mecanismo muy útil para articular la cooperación territorial en el ámbito de la gestión pública local. Pudiendo jugar, en el presente y en el futuro, un papel determinante en el desarrollo de la autonomía local.

\section{ADDENDA FINAL}

Sin perjuicio de las consideraciones anteriores, debemos poner de relieve que, con carácter posterior a la finalización del presente trabajo, el Tribunal Constitucional ha procedido a dictar dos importantes sentencias en materia de asociaciones.

Se trata de la Sentencia núm. 133/2006 (ponente: D. ${ }^{a}$ Elisa Pérez Vera) y la Sentencia núm. 135/2006 (ponente: D. Manuel Aragón Reyes), ambas con fecha 27 de abril, y en las que se resuelven sendos recursos de inconstitucionalidad presentados por el Parlamento de Cataluña y el Gobierno de la Nación frente a la LODA y la LCA, respectivamente.

El contenido argumental de dichas Sentencias se refiere principalmente a la distribución de competencias entre el Estado y las Comunidades Autónomas en materia de asociaciones, si bien en éstas se contienen también interesantes pronunciamientos sobre algunas de las cuestiones que hemos apuntado a lo largo de nuestra exposición.

En este sentido, podemos destacar especialmente el F.J. 5 de la mencionada STC 135/2006, de 27 de abril, en el que se analiza la exigencia de que la organización y funcionamiento de las asociaciones deba tener carácter democrático, planteándose, asimismo, en los fundamentos jurídicos 7 y 14 respectivamente, la posible extensión de la titularidad del derecho de asociación a las personas jurídicas, tanto públicas como privadas, o el alcance de los derechos y deberes de las personas asociadas.

Finalmente, tanto en la STC 133/2006 (F.J. 5) como en la STC 135/2006 (F.J. 11), se afrontan cuestiones relativas a la regulación de la forma de gobierno y administración de las asociaciones, centrando su atención esencialmente en lo que se refiere a la regulación de la estructura interna de las asociaciones. 